\title{
城市公共服务设施与人口是否匹配? 基于社区生活圈的评估
}

\author{
常 飞 ${ }^{1,2}$, 王录仓 $3^{*}$, 马 玥 $^{3}$, 严翠霞 ${ }^{3}$, 刘海洋 ${ }^{3}$ \\ (1. 深圳大学建筑与城市规划学院,广东 深圳 $518000 ; 2$. 深圳大学智慧城市研究院,广东 深圳 518000 ; \\ 3. 西北师范大学地理与环境科学学院, 兰州 730000)
}

\begin{abstract}
摘 要: 公共服务设施是城市社会服务最基本的承载体,公共服务设施分配的公平与否,事关城市健康发展和社会 公正运行。目前由于城市微观尺度人口数据的缺失, 鲜有研究将供给侧(公共服务设施)与需求侧(人口)统一起 来。鉴于此,论文以互联网地图 API 为支撑, 建立了 $5 \mathrm{~min} 、 10 \mathrm{~min} 、 15 \mathrm{~min}$ 三个层级的社区生活圈, 并模拟了高分辨 率、高精度的人口分布图, 对案例城市兰州市的公共服务设施与人口的匹配关系进行了详细评估。研究发现: (1) 不同类型公共服务设施与人口的匹配关系差异较大,但均表现为区级中心匹配状况较好,城市边缘区域漏配较 多; (2) 兰州市大部分公共服务设施与人口匹配关系两极分化性较强, 即高配型与漏配型生活圈数量较多, 适配型 与低配型生活圈数量相对较少; (3) 从中、高匹配度的生活圈的比例来看,各级出行类、就餐类、娱乐类、医疗类设施 (10 min 生活圈对应的社区卫生服务中心除外)的覆盖范围最广, 各级养老类设施和基层文化设施的配置严重不 足, 其他设施介于两者之间。对于暴露出的问题需要查漏补缺, 研究认为, 当前公共服务设施规划的重点在于解决 养老类设施普及性低和城市边缘区各类公共服务设施配置不足的问题。
\end{abstract}

关 键 词: 公共服务设施; 社区生活圈; 匹配关系; 适配性; 人口;兰州市

公共服务设施是城市生产生活的基本保障,公 共服务设施分配过程和结果的公平公正性,影响社 会健康良好的运行。公共服务设施目前普遍存在 地域分配不均、供需结构失衡等问题,这一问题在 中国也较为突出 ${ }^{[1-3]}$ 。近几十年来,中国城市经历了 高速的城市规模扩张和深刻的社会经济改革, 城市 发展驱动力、基本组织单元、管理模式均发生了变 革, 这一变革投射在城市公共服务上, 引起城市公 共服务设施配置模式的转变。计划经济时期, 城 市在中国是国家工业化实现的物质基础,服务于 工业建设 ${ }^{[4]}$ 。为实现快速工业化,城市政府推行社 会主义单位制度, 以工作单位为基本单元组织城市 居民的生产生活, 除了为居民提供工作、居住空间
外，还提供教育、医疗等公共服务设施。单位制度 的优势是营造了职住接近、社会平等和土地混合利 用、归属感较强的“熟人社区” ${ }^{[5-7]}$ 。但是, 由于单位 本身实力的差距, 公共服务设施配置水平也不尽相 同,而且单位之间公共服务设施并无积极的共享机 制, 造就了公共服务设施的破碎化、重复布局及缺 乏系统性等问题 ${ }^{[8]}$ 。

改革开放后, 随着非公经济体的快速崛起和城 市化高速扩张, 单位制度逐渐成为城市发展的阻碍 性因素 ${ }^{[9]}$ 。因此, 中国逐步废除了住房实物分配制 度, 推动土地利用制度改革和商品化住房制度改 革, 原来以单位为组成细胞的城市组织系统逐渐瓦 解 ${ }^{[10]}$ 。城市也开始摒弃生产导向的发展模式,通过

收稿日期 : 2020-09-14; 修订日期 : 2020-11-19。

基金项目: 国家重点研发计划项目(2018YFB2100704)。 [Foundation: National Key Research and Development Project, No. 2018YFB2100704.]

第一作者简介:常飞(1994-), 男, 甘肃庆阳人,博士生,主要研究方向为城市建成环境信息技术。E-mail: 326354132@qq.com

*通信作者简介:王录仓 $(1967$ - ), 男, 甘肃天水人,教授,博士生导师, 主要研究方向为城乡发展与规划。

E-mail: wanglc007@nwnu.edu.cn

引用格式: 常飞, 王录仓, 马玥, 等. 城市公共服务设施与人口是否匹配? 基于社区生活圈的评估 [J]. 地理科学进展, 2021, 40(4): 607-619. [Chang Fei, Wang Lucang, Ma Yue, et al. Do urban public service facilities match population demand? Assessment based on community life circle. Progress in Geography, 2021, 40(4): 607-619. ] DOI: 10.18306/dlkxjz.2021.04.006 
“出城人园”等政策推动工业郊区化, 促进城市向消 费与服务功能转型 ${ }^{[1]}$ 。与此同时, 政府和市场全面 取代了单位直接向居民提供公共服务设施, 以城市 规划统筹公共服务设施的配置。

在原有城市规划体系中, 中国公共服务设施配 置是以理想状态下土地所能承载的居住人口为参 照口径, 以规划地块为单元, 按照 “千人指标” (每千 人设施拥有数量或每千人平均拥有面积)和“服务 半径”定量配给。但在现实中, 规划地块与 “服务半 径”无法形成良好的对接, 现实人口分布也与理想 承载人口容量相差悬殊, 规划的公共服务设施量与 实际人口量之间也难以有效匹配, 使得城市公共服 务设施配置问题重重, 难以应对快速郊区化和市场 持续强化刺激产生的城市职住分离、通勤距离拉 长、设施配置不均衡、居民归属感消退等问题 ${ }^{[6]}$ 。对 于这一问题, 大量学者进行了积极探索, 在借鉴日 本、韩国生活圈建设经验的基础上,引人了一种新 的公共服务设施配置模式一一基于居民日常生活 圈的公共服务设施配置体系, 并在城市规划实践中 得到了应用。

住房和城乡建设部2018年发布的《城市居住区 规划设计标准(GB50180-2018)》(下文简称为《居 住区规划标准》) ${ }^{\mathbb{1}}$ 首次明确提出了以 $15 \mathrm{~min} 、 10$ $\min 、 5 \mathrm{~min}$ 和居住街坊 4 级生活圈为单元的服务设 施配套控制指标。同时《城市公共服务设施规划标 准(GB50442 征求意见稿)》(下文简称为《公共服务 设施规划标准》) ${ }^{2}$ 也体现了按不同层级衔接配套公 共服务设施的理念。有一些地区已经开展了相关 规划并准备实施, 例如上海市 ${ }^{[12]}$ 与兰州市 ${ }^{3}$ 相继出 台了 $15 \mathrm{~min}$ 生活圈规划措施, 也做了相应的规划方 案。然而, 在具体的规划实践过程中, 生活圈并没 有突破“原有社区”的巢臼, 或者只是简单地将相邻 社区合并,形成以社区为基础的生活圈。尤其是没 有解决 $15 \min (10 \mathrm{~min}$. $5 \mathrm{~min}$ )生活圈的 “原点”究竟 在哪里, 使得划出的圈实际上处于模糊状态或人为 划定状态。而且, 尽管“营造 15 分钟社区生活圈, 补 齐公共设施短板”已成为了共识, 但究竟在什么状 态公共服务设施才能满足生活圈内居民的各种需
求, 目前还未形成统一共识。也就是说, 公共服务 设施的供需匹配关系并没有得到理论和实践上的 解决。

城市日常生活圈是指居民为了满足生产、生 活、社会交往需求, 以自身居住地为中心, 开展通 勤、通学、休闲、社会交往、就医等活动形成的圈域 范围 ${ }^{[13]}$ 。20世纪90年代左右, 柴彦威 ${ }^{[14]}$ 、陈青慧等 ${ }^{[15]}$ 将这一理论引人中国, 开展了一些实证研究。2010 年以后, 随着中国城市建设由增量向存量的转变, 城市生活圈理论开始进人了应用研究阶段, 最典型 的应用方向是以生活圈为单元的公共服务设施分 配、评估和优化实证研究。尽管大量学者对如何划 定生活圈, 并以此为单元评估公共服务设施的可达 性或覆盖率进行了广泛关注 ${ }^{[16-21]}$, 但鲜有文献从生 活圈视角出发聚焦于供给侧与需求侧的匹配关 系。因此, 本文在 “以人为本” 的生活圈理念指导 下, 将城市活动主体(即居民)的出行范围和潜在需 求纳人公共服务设施评估中, 以多尺度居民日常生 活圈为单元, 以高精度模拟人口数据和互联网地图 开放数据为基础, 深人考察公共服务设施和人口之 间的匹配关系。这对于实现公共资源均等化、精准 化配置, 有效应对居民差异化需求具有重要的理论 和现实意义 ${ }^{[22]}$ 。

\section{1 研究区域与数据}

\section{1 研究区概况}

本文选取兰州市作为案例区。兰州市是甘肃 省省会、西部地区重要的中心城市和综合交通枢 纽, 是中国典型的河谷带状城市, 受地形和河流的 强烈约束,城市功能分区明显,组团特征显著,基础 设施和公共服务设施配置效率低。本文研究区域 为兰州市的建成区, 范围与《兰州市第四版城市总 体规划》 ${ }^{(4)}$ 中的建成区范围一致, 涉及城关区、七里 河区、安宁区和西固区 4 个区。截至 2018 年末, 兰 州市户籍人口 328.47 万人, 其中, 城镇人口 231.25 万人, 建成区面积合计 $179.46 \mathrm{~km}^{2}$, 地区生产总值 2732.94 亿元 $^{5}$ 。

\footnotetext{
(1) http://www.mohurd.gov.cn/wjfb/201811/W020181130044801.pdf。

(2) http://www.mohurd.gov.cn/zqyj/201805/t20180522_236167.html。

(3) 兰州市十五分钟生活圈配套设施规划研究与导则, http://zrzyj.lanzhou.gov.cn/art/2020/2/25/art_10563_857371.html。

(4)《兰州市第四版城市总体规划》,http://zrzyj.lanzhou.gov.cn/art/2017/9/19/art10426554643.html。

(5)《兰州市统计年鉴(2019年)》,http://tjj.lanzhou.gov.cn/art/2019/12/11/art_4866_834601.html。
} 


\section{2 数据来源}

\subsubsection{DLAPI 与POI数据}

划定生活圈所需的出行路线规划数据(即通俗 所说的百度地图导航数据)通过 Python 程序批量获 取自百度地图开放平台中的 web 服务 API(http://lbsyun.baidu.com/index.php? title=webapi)下的轻量级 路线规划服务(Direction Lite API, DLAPI)。DLAPI 支持中国大陆地区驾车、骑行、步行、公交路线规 划, 请求的返回参数包含起终点坐标、路段距离、路 段耗时等信息。此数据考虑了交通方式、路网路线 和实时路况,所以比较契合现实生活。本文用到的 居住区 POI数据获取自高德开放平台。根据需求, 在研究区内获取了 53 种 26735 个公共服务设施点, 2404 个居住小区。

\section{2 .2 人口分布数据}

目前城市人口研究方面面临着人口数据收集 难、分辨率不足、精度低等问题, 官方公布的人口统 计数据只能精确到街道办层面(难以与社区或生活 圈空间尺度对应起来), 但它更新慢, 空间分辨率 低, 难以满足需求。这给以往的同类研究造成了巨 大的困难。鉴于此,本文以 Worldpop 人口空间统计 中的“China Population 2019”格网数据(本文简称为 WP 格网人口)和百度热力图为基础, 运用机器学习 算法模拟了城市高分辨率、高精度的人口分布图。

(1) 基础数据简介

WP 格网人口数据集为 Geotiff格式, 分辨率为 3 弧秒 (在赤道处约为 $100 \mathrm{~m}$ ), 数据的具体介绍参见 该网站(https://www.worldpop.org/geodata/summary? $\mathrm{id}=6275)$ 的数据描述文档和推荐文献。该数据在城 市尺度上有着良好的表现力, 但在更小的城市内部 空间尺度上, 其精确度并不理想, 存在较大的误差 (图 1), 故此本文借用百度热力图以提高此数据的精 度。百度热力图是百度公司在 2011 年推出的一款 大数据可视化产品, 该产品是基于位置服务的手机 用户地理位置数据, 当智能手机使用者访问百度产 品时,其所携带的位置信息便被记录下来,形成数 字足迹, 结果在百度地图上以不同的色相和亮度显 示 ${ }^{[23]}$ 。为了尽可能避免流动性人口和非常规人群 活动的影响, 本文基于对当地居民的作息规律的认 知, 选择人口流动性不强、户外活动较少的当地正 常工作日的休息时段(20:30 22:00)为获取数据的时 段,本文采集了 2019 年 8 月 26-28日,连续 $3 \mathrm{~d}$ 休息 时段热力图, 采用平均采样法合成本文最终应用的
热力图(图 2b)。

(2) 高精度人口分布数据模拟

用监督回归学习模型中的随机梯度下降模型 (SGDR) 来模拟人口分布, SGDR 模型形式简单、高 效、便于实施,超参数的多样性和特征缩放的敏感 性给模型提供更多的操控性。可以通过训练调整 损失函数(loss) 和惩罚项(penalties)的配置, 优化提 升模型的性能, 强化拟合效果。由于百度人口热力 图和 WP 格网人口分布本身具备线性关系, 且数据 量庞大,适用于此模型。具体模拟方法为: 按 $100 \mathrm{~m}$ 格网提取 WP 人口数据和百度热力图的热力度, 作 为输人层; 估算 2019 年街道办人口数据(将 2019 年 全城人口增长量分加至 2010 年“六普”时的街道办 数据中), 作为训练结果层; 这 2 个数据共同组成训 练集,在 SGDR 模型中训练优化后, 分行政区模拟 $100 \mathrm{~m}$ 格网尺度人口分布图。整合后, 模拟结果如 图 $2 \mathrm{~d}$ 所示, 与统计数据和 WP 格网数据相比, 模拟 数据明显优于原数据(图 1)。

\section{2 研究方法}

\section{1 生活圈划定方法}

\subsection{1 生活圈圈层体系划定}

居民日常生活圈是建立在居民日常出行行为 基础之上,学者们一般通过调查居民日常出行范围 和目的, 对其进行归纳和总结, 确定生活圈体系。 如刘嫱 ${ }^{[18]}$ 和孙道胜等 ${ }^{[247}$ 将居民日常出行范围划分为 3 个尺度:(1) 社区级尺度的日常生活圈, 居民与服

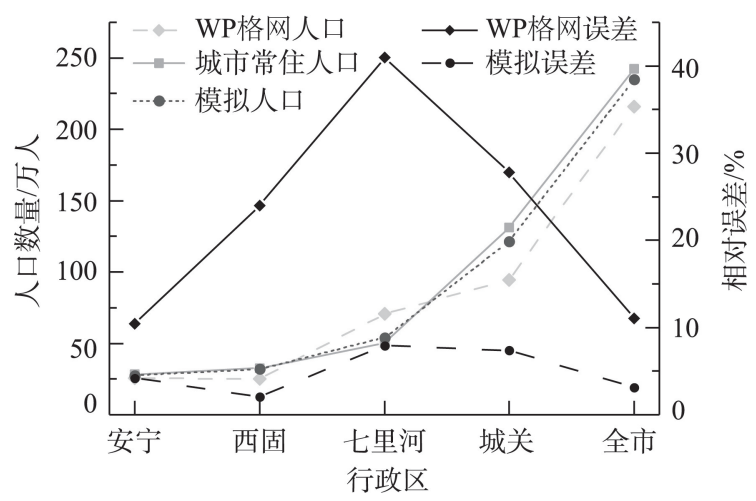

注: 城市常住人口=常住人口-农业人口; 模拟人口=本文 $100 \mathrm{~m}$ 格网人口模拟结果。

图 1 WP人口、模拟人口与统计人口误差

Fig.1 Error of WP population and simulated population compared to the statistical population 
(a) WP $100 \mathrm{~m}$ 格网人口分布

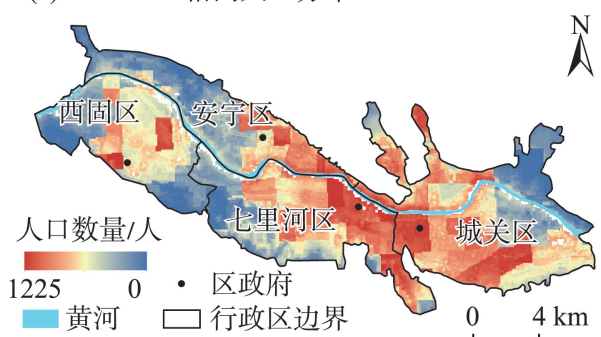

(c) “六普”街道办人口分布

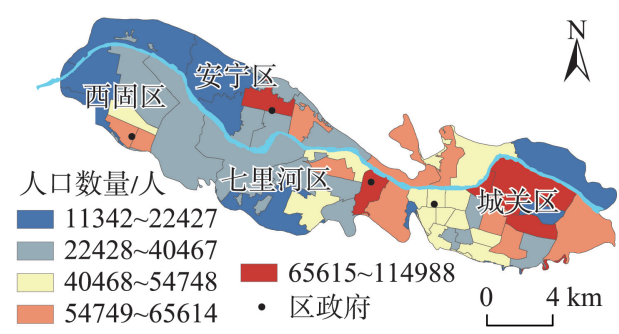

(b) 百度热力图

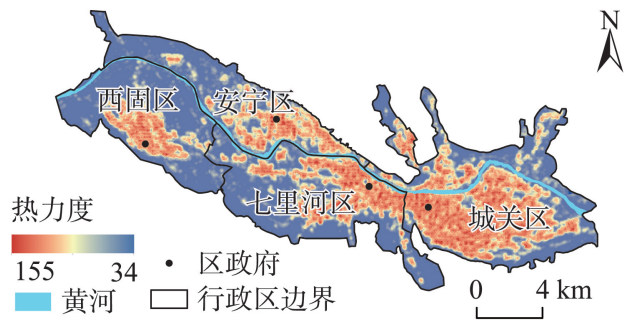

(d) $100 \mathrm{~m}$ 格网人口模拟结果

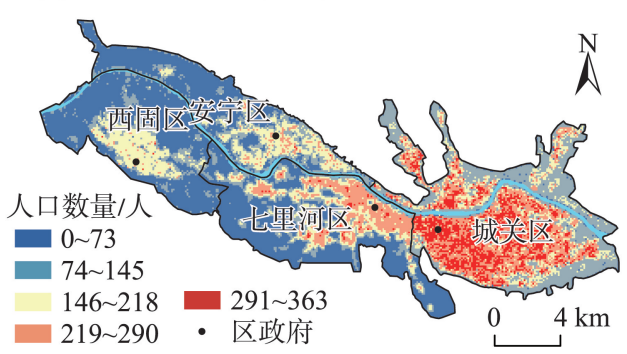

图 2 研究区人口分布

Fig.2 Population distribution in the study area

务设施之间互动频繁; (2) 居住一工作通勤形成的 生活圈, 在居民生活中扮演着极其重要的角色, 居 民与设施之间联系的频次也相对较高; (3) 居民偶 发式出行形成的机会生活圈, 它是前 2 个生活圈在 空间中的扩展和延续, 居民出行互动的频次较低。 本文只关注居民活动频率较高的社区生活圈, 参考 《上海市 $15 \mathrm{~min}$ 社区生活圈规划导则(试行)》 ${ }^{[12]}$ 和 《居住区规划》中的社区生活圈的细分方式(步行时 长 5、10、15 min 三个的社区生活圈), 这里同样将社 区生活圈划分为 $15 、 10 、 5 \mathrm{~min}$ 生活圈 3 个二级圈层。

\subsection{2 居住区与生活圈的整合}

(1) 居住区的整合

城市生活圈规划因其从居民个体日常生活出 发的特性而受到学术界和规划界的关注, 生活圈源 于城市居民(人), 最终归宿于居民(人)。然而城市 人口规模巨大、需求多元、行为各异, 显然倘若以个 体的人为基准划定日常生活圈,无异于缘木求鱼, 不仅无法划定生活圈, 更无法解决基础设施与公共 服务设施的配置问题, 因此必须将个体的人转化为 群体的人。在人口整合的过程中, 必须考虑人口分 布的“现世性”, 城市人口总是处于空间位移状态, 且空间分布不均衡, 但由于人口分布的实际载体是 各类居住区, 因此可依托居住区(小区、居住区 POI 数据) 将分散的、个体特性的人整合成一定规模、群 体特性的人。然而受居住区类型、建成年代、规模
和相邻关系的影响, 必须对居住区进行整合, 使其 成为真正划定生活圈的基座。以该居住区的质心 为 “原点”, 以 DLAPI返回的出行时耗为半径划定城 市日常生活圈。

事实上, 商品化住房改革以来, 职一住一服务 一体化的单位大院逐渐蜕变和转型, 现存单位大院 基本突破了公共服务设施“自给自足”的发展模式, 而且随着单位大院管理权属的转变,其内部原有公 共服务设施也开始对外开放。新崛起的商业住宅 的开发主体以营利为目标, 为实现利润最大化, 将 公共服务设施推向了居住区外部空间。因此, 现有 居住区均是依赖外部空间的公共服务设施来保障 其正常运转的非“自给自足”式社区,相邻居住区完 全有共享公共服务设施的现实条件。在此背景下， 对居住区进行整合, 可促进公共服务设施共建共 享, 提高土地利用效率, 优化城市内部空间结构。 具体整合方法是: 将小于一定距离的居住区合并为 一个区, 这一距离选定为兰州市居住小区外接圆的 平均半径 ${ }^{\oplus}$ (记为 $\min d, \min d=72 \mathrm{~m}$ ), 即将间距小于 $\min d$ 的多个小区随机合并至其中一个居住区(第一 次整合)。之后, 再调用预制程序以整合后的居住 区为原点划定生活圈。

(2) 生活圈的整合

虽然居住区经过了整合,一定程度上降低了生 活圈划定结果的圥余度, 但生活圈的数量依然很

(6) 数据来源于抓取自高德地图的面状数据。 
多, 不同生活圈之间互相重叠的部分也较大, 因此 有必要进行第二次整合。根据“四舍五人法”原则, 将重叠率超过 $50 \%$ 的 2 个(或多个)生活圈合并为同 一个生活圈。经过这 2 次整合后, 生活圈之间的重 合度明显下降。此外, 由于百度地图部分地区的数 据集存在一些瑕疪, 会导致生活圈划定出现异常情 况, 最突出的表现为生活圈斑块明显过小和生活圈 延伸到了步行无法到达的区域(如黄河水域、山体 等)。对此还需再进一步处理, 首先, 对于面积过小 的生活圈予以剔除, 共剔除了面积小于小区平均面 积的 $5 \mathrm{~min}$ 生活圈 28 个、面积小于 $5 \mathrm{~min}$ 生活圈平 均面积的 $10 \mathrm{~min}$ 生活圈 5 个、面积小于 $10 \mathrm{~min}$ 生活 圈平均面积的 $15 \mathrm{~min}$ 生活圈 6 个; 其次, 对于无法到 达区域, 使用黄河水域和城市建成区范围进行裁 剪。此外, 异常点(明显过远或过近)的出现会扰乱 生活圈的范围, 对此, 比照道路底图和谷歌影像图 进行修正。

\subsection{3 生活圈的空间边界划定}

以 $5 \mathrm{~min}$ 生活圈划定为例。如图 3 所示, 首先, 提取合并处理后的任意一个居住区(具有经纬度、 类型、名称等属性), 以它为中心, 在理想最大范围 内(即最大跨度 $\mathrm{MD}$, 本文采用 $5 \mathrm{~min}$ 健康成人步行 最大上限, 设 $\mathrm{MD}=1000 \mathrm{~m}$ ) 创建跨度适当的网格点 (即采样精度 $\mathrm{PD}$, 本文设 $\mathrm{PD}=100 \mathrm{~m}$ ) 作为居民出行 的潜在目的地; 之后, 以网格点作为起点(origin), 以 选定的居住区为终点(destination), 应用Python 程序 调用DLAPI接口, 批量循环获取所有起点至终点的 交通耗时(Duration), 存储为文本文件; 在此之后, 结 合 Arcpy (ArcGIS 的 Python 模块)利用居住区和等 间距点的坐标与时耗信息生成生活圈的圈域范围; 最后, 对所有居住区进行循环调用, 合并所有生活 圈,生成结果图层。经过整理最终共划分出了 835 个 $5 \mathrm{~min}$ 生活圈、288 个 $10 \mathrm{~min}$ 生活圈、147 个 $15 \mathrm{~min}$ 生活圈。

图 4 展示了一个居住小区(城关区水云阁小区) 的 3 类生活圈的划定结果, 从结果来看, 以 DLAPI 为基础划定的 4 类生活圈充分考虑了道路、围墙、出 人口等连通要素和障碍要素, 结果更贴合实际, 而 以《居住区规划标准》建议的生活圈半径 (5 min 为 $300 \mathrm{~m} 、 10 \mathrm{~min}$ 为 $500 \mathrm{~m} 、 15 \mathrm{~min}$ 为 $1000 \mathrm{~m}$ )划定的圈 域缺乏对现实地理条件的考虑, 是理想化的表达, 忽略了真实城市中异质性的广泛存在 ${ }^{\text {? }}$ 。

\section{2 评估方法与依据}

\subsection{1 生活圈与公共服务设施对应方式}

各类公共服务设施的服务方式、服务范围、服 务层次不尽相同,用统一空间尺度分析会造成结果 的误差, 因此需要将公共服务设施与各类生活圈对 应起来。依据中国相关行业规范与标准(《居住区 规划标准》《公共服务设施规划标准》《城市绿地分 类标准(CJJ/T85-2017)》《城市消防站建设标准(建

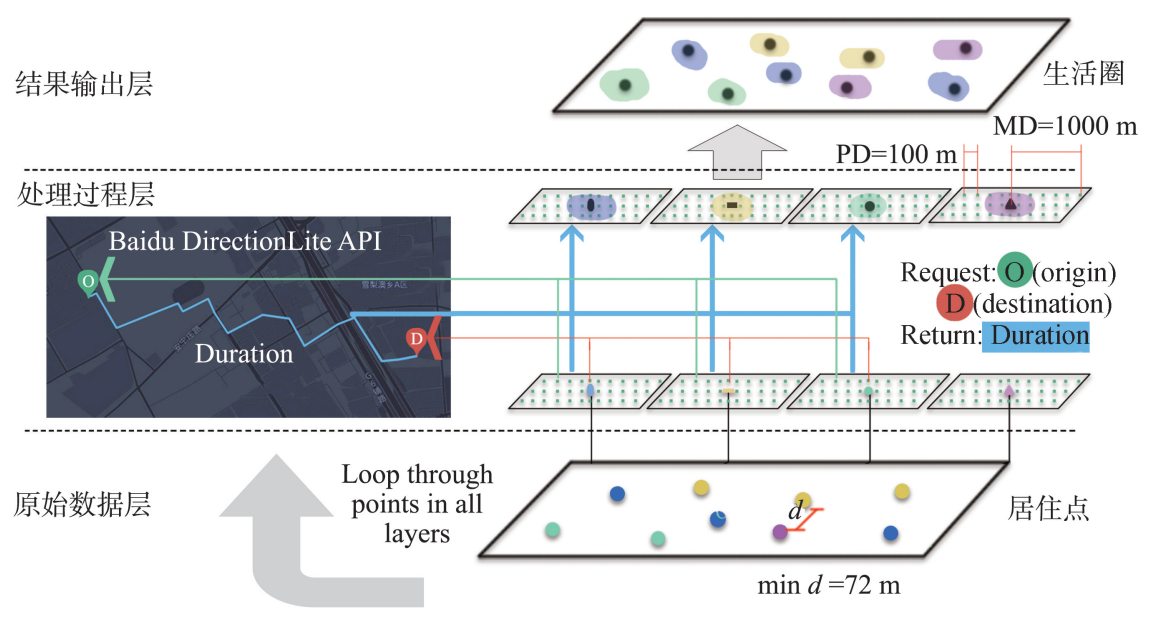

图 3 调用API划定 5 min生活圈方法示意图

Fig.3 Method of calling API to delimit a five-minute life circle

(7) 为了便于后续研究使用本文提出的生活圈划定方法,本文将基础数据获取方式、生活圈划定方式分别开发为独立软件和基于 ArcGIS平台 的Python 脚本工具集, 具体介绍详见作者CSDN 网站(https://download.csdn.net/download/antgoing5230/12520523; https://download.csdn.net/ download antgoing5230/12520519)。 
标 152-2017)》等)对公共服务设施服务范围(服务 半径或行政辖区)的要求, 以服务范围与生活圈范 围为依据, 将范围相同的公共服务设施与生活圈一 一对应(表1)。此外, 需要说明的是, 在选择公共服 务设施的时候, 结合实际情况进行了与时俱进的更 新, 既选用了一些传统公共服务设施, 又加人了一 些近些年来的新兴设施。

\subsection{2 评估依据}

以“千人指标” $G_{i}$ (即 1000 人应配置设施量) 作 为适配性评判标准。此评判标准面临 3 种不同的情

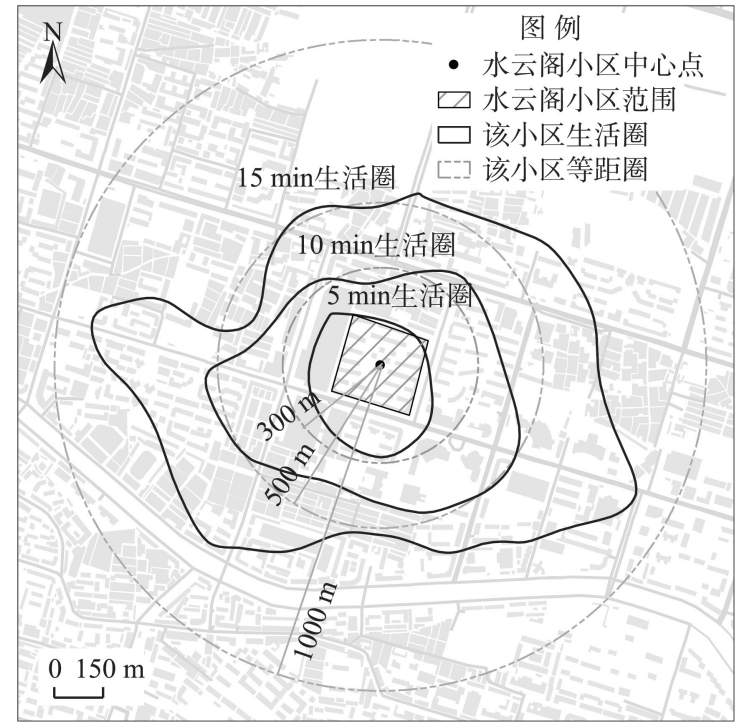

图 4 水云阁小区生活圈划定示意图

Fig.4 Sketch map of the life circle of Shuiyunge Community
况:第一种情况是《居住区规划标准》《公共服务设 施规划标准》等相关行业规范中明确规定了“千人 指标”, 对此, 统一使用相应规范中的指标要求, 此 类设施包含老年人日间照料中心、养老院、文化活 动中心、便利店等; 第二种是《居住区规划》中明确 规定了生活圈的人口容量 $(5 \mathrm{~min}$ 生活圈人口 $=$ 5000 12000 人、 $10 \mathrm{~min}$ 生活圈人口 $=15000 \sim 25000$ 人、 $15 \mathrm{~min}$ 生活圈人口 $=50000 \sim 10000$ 人)、应配置设 施与建筑面积, 由此推算应配置量, 则 $G_{i}=$ 推算配置 量/生活圈规范人口 $\times 1000$, 此类设施有中小学、幼 儿园、公园等; 第三种是相关行业规范未指明设施 量与人口关系的, 此类设施包含餐饮、物流速递、银 行网点等, 则 $G_{l}=$ 生活圈平均设施量区间/生活圈规 范人口 $\times 1000$, 为保证此种计算方法泛化能力, 为平 均值加人 $\pm 50 \%$ 浮动空间, 形成生活圈平均设施量 区间,结果如表 2 所示。匹配度计算方法如下:

$$
\begin{gathered}
R_{i}=\mathrm{RQ}_{i} / \mathrm{Rpop} \times 1000 \\
\mathrm{Sp}_{i}= \begin{cases}\text { 适配 } & R_{i} \in G_{i} \\
\text { 高配 } & R_{i}>G_{i} \\
\text { 低配 } & R_{i}<G_{i}\end{cases}
\end{gathered}
$$

式中: $R_{i}$ 为实际 $i$ 设施千人拥有量, $\mathrm{Rpop}$ 为生活圈中 实际人口数量, $\mathrm{RQ}_{i}$ 表示生活圈实际设施数量 $; \mathrm{Sp}_{i}$ 表示 $i$ 类设施的匹配关系(即匹配度), 它表示实际 $i$ 设施千人拥有量与 $i$ 设施千人标准量之间的偏差程 度。“适配”表示公共服务设施数量与人口相匹配, “高配”是指设施配置量相对人口规模超前, “低配” 是指设施配置滞后于人口, $R_{i}=0$ 则为漏配。

表 1 各生活圈配套设施项目

\begin{tabular}{|c|c|c|c|}
\hline \multirow{2}{*}{ 大类 } & \multicolumn{3}{|c|}{ 社区生活圈 } \\
\hline & $5 \min (\mathrm{I}$ 级 $)$ & $10 \min (\mathrm{II}$ 级) & $15 \min$ (III级) \\
\hline 文化 & & & 文化活动中心 \\
\hline 教育 & 幼儿园 & 小学 & 初级中学、完全中学 \\
\hline 养老 & 老年人日间照料中心、居家养老服务中心 & 社区老年活动中心(室) & 养老院 \\
\hline 医疗 & 诊所、药店 & 社区卫生服务中心(站) & \\
\hline 出行 & 公交车站、路侧停车位、停车场 & 公交车站、地铁站点 & \\
\hline 就餐 & & 饭店餐馆、糕点甜品店 & \\
\hline 食材 & & 大型生活超市,生鲜市场 & \\
\hline 消费 & 便利店、商店,美发店,洗衣店 & & 专营商品店、美容美甲 \\
\hline 便民网点 & & 电讯、银行网点(包括 ATM) & 邮局、物流速递 \\
\hline 娱乐 & & & 娱乐设施、休闲设施 \\
\hline 养生 & & & 洗浴足疗推拿、医疗保健、健身房 \\
\hline
\end{tabular}

Tab.1 List of supporting facilities in each life circle 


\section{3 评估结果}

以表 1 所示设施与生活圈对应关系为基础, 以 表 2 所示 “千人指标” 为标准, 从各类生活圈审视设 施与人口之间的匹配关系。从结果来看, 各类生活 圈存在一个普遍特征: 匹配度较高的生活圈倾向在 城市或区级中心区域分布,城市边缘往往发展成为 无设施覆盖的“死角”,这是城市中心极化效应的集 中体现。但是, 在配置方式、配置主体、政策支持力 度等差异化作用机制下, 不同区位、不同类型生活 圈的设施一人口匹配度不尽相同, 根据公共服务设 施与人口的高配与适配型生活圈覆盖范围的差异, 把各类设施分为广泛覆盖型、中等覆盖型和低覆盖 型 3 类。

\subsection{5 min 生活圈适配性}

$5 \mathrm{~min}$ 生活圈对应的 I 级设施是便民服务的基 层设施(表 1$)$, 各类设施高配与适配型生活圈覆盖范 围差异较大(图 5)。

(1) 广泛覆盖型 : 大部分 $5 \mathrm{~min}$ 生活圈的医疗设 施和出行设施以适配和超前配置为主, 这 2 类设施 高配与适配型的生活圈比例分别为 $63 \%$ 和 $74 \%$, 覆 盖范围广泛。它们的低配型生活圈占比最低, 均不 足 $10 \%$ 。二者的空间分布模式也较为相似,形成了 5 个空间组才，即 4 个区级行政单元的中心区域和 雁滩片区, 组团之间和组团之外的边缘地带漏配现 象严重。表明医疗类设施和出行类设施作为刚性 需求, 大部分区域得到了保障, 但城市边缘区域配 置不足。

(2) 中等覆盖型: 消费类和教育类设施的高配 与适配型生活圈的覆盖范围相对较小。其中, 消费 类设施以适配与低配为主, 适配与低配型生活圈总 占比为 $64 \%$ 。 $5 \mathrm{~min}$ 生活圈对应的消费类设施通常 是由个体户经营的便民商店与洗衣店等设施, 其分 布格局与市场作用密不可分, 在强烈竞争环境中,
高于人口的超前配置会导致边际效益的下降,最终 设施的配置量会发展至与人口动态平衡适配的状 态,这集中体现了市场供给设施的优势。同样,城 市边缘区是消费漏配型生活圈的主要分布区, 这体 现了市场供给的劣势, 潜在收益较低的区域,往往 不是市场角逐的对象。

教育类设施与人口适配关系的两级分化现象 最为严重。教育高配型生活圈的比例为 $34.3 \%$, 漏 配型生活圈的比例为 $56.2 \%$, 两者从核心区到边缘 区混合分布。5 min 生活圈对应的教育设施为幼儿 园,在中国城市规划的相关规范中, 5 min 生活圈对 应的教育设施(幼儿园)的服务半径为 $300 \mathrm{~m}$, 学前 教育通常是在居住小区开发的同时附带建设, 由 于难以统筹协调, 实际布局距离往往与规范距离 不符。

(3) 低覆盖型 : 这一类型有养老类设施。适配 与高配型生活圈数量少, 覆盖范围小, 漏配型生活 圈比例高达 $95.7 \%$, 配置量全面滞后于人口。仅有 的适配与高配型生活圈散布在城关区与西固区,而 且与其他设施的向心性分布不同,养老设施主要分 布在中间地带和边缘地带。中国已经步人老年社 会, 《兰州市统计年鉴(2019年)》显示,截至2018 年 末, 兰州市 65 岁以上人口为 48.98 万人, 占常住人口 的 $13.05 \%$, 老龄人口基数庞大, 且在持续加剧, 问题 十分突出。在当前中国文化理念和养老政策机制 下, 5 min 生活圈对应的居家式养老将成为中国主 要的养老形式。然而, 与之相悖的是,兰州市养老 设施缺口非常巨大, 大部分区域严重失配。

\section{$3.210 \mathrm{~min}$ 生活圈适配性}

$10 \mathrm{~min}$ 生活圈与 $5 \mathrm{~min}$ 生活圈的同类设施与人 口的匹配度相比,变化不大(图 6), 只有医疗类设施 的高配型生活圈数量明显下降, 同时, 靠近城市中 心生活圈的教育类设施配置量有大幅提高。高配 与适配型生活圈的覆盖范围如下所示。

表 2 各类生活圈中各设施的千人标准配置量 $\boldsymbol{G}_{\boldsymbol{i}}$

Tab.2 Standard of public service facilities per 1000 person in various life circles $G_{i}$

(个/千人)

\begin{tabular}{|c|c|c|c|c|c|c|c|}
\hline 大类 & $5 \min$ (I级) & $10 \min$ (II 级) & $15 \min$ (III 级) & 大类 & $5 \min$ (I级) & $10 \min (\mathrm{II}$ 级) & $15 \min$ (III级) \\
\hline 文化 & & & {$[0.01,0.02]$} & 食材 & & {$[0.08,0.4]$} & \\
\hline 教育 & {$[0.083,0.2]$} & {$[0.04,0.067]$} & {$[0.03,0.14]$} & 消费 & {$[1,3]$} & & {$[0.07,0.42]$} \\
\hline 养老 & {$[0.04,0.2]$} & {$[0.04,0.067]$} & {$[0.01,0.02]$} & 便民网点 & & {$[0.12,0.6]$} & {$[0.15,0.45]$} \\
\hline 医疗 & {$[0.33,0.8]$} & {$[0.01,0.033]$} & & 娱乐 & & & {$[0.06,0.36]$} \\
\hline 出行 & {$[0.25,1.4]$} & {$[0.12,0.46]$} & & 养生 & & & {$[0.03,0.18]$} \\
\hline 就餐 & & {$[2.92,4.87]$} & & & & & \\
\hline
\end{tabular}


(a) 医疗类设施

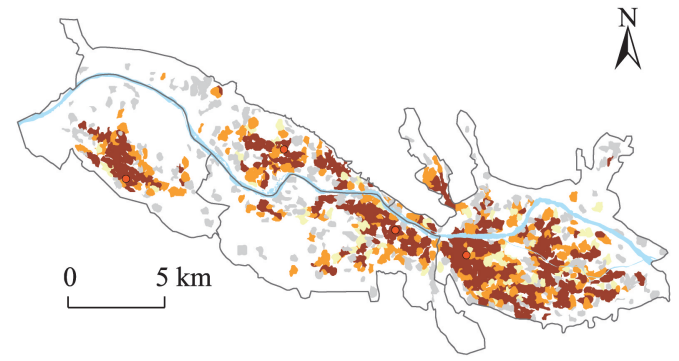

(c) 出行类设施

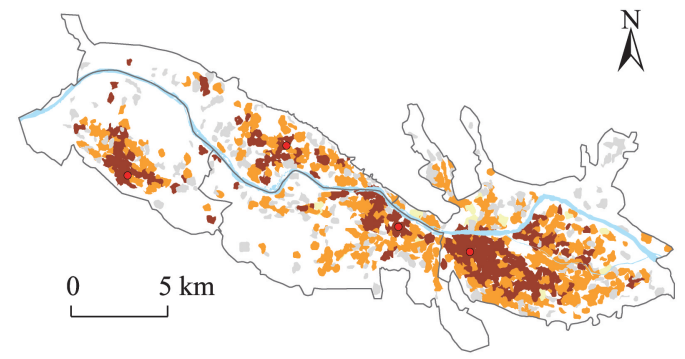

(e) 养老类设施

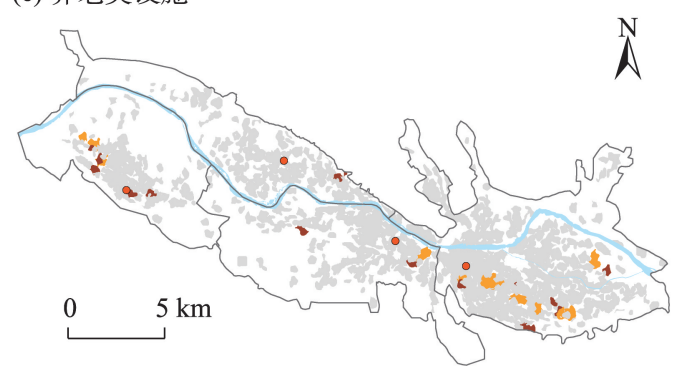

(b) 教育类设施

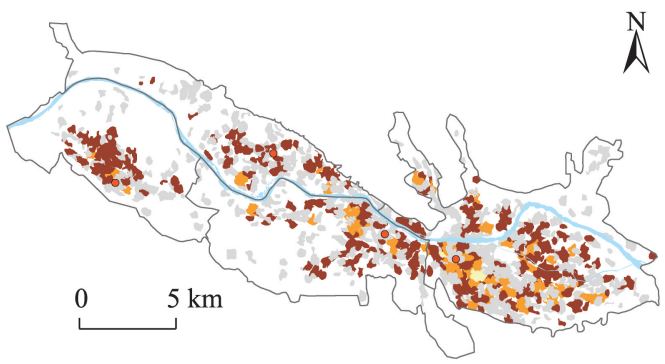

(d) 消费类设施

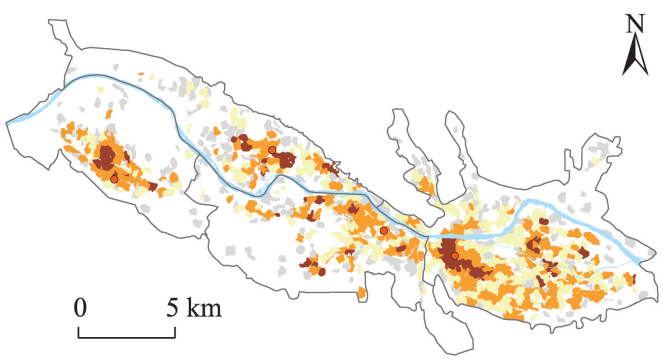

图 5 兰州市 $5 \mathrm{~min}$ 生活圈设施适配性

Fig.5 Matching relationships of public service facilities in five-minute life circle of Lanzhou City

(1) 广泛覆盖型 : 这一类型有就餐类、出行类和 便民网点类设施。就餐类设施以高配型生活圈为 主, 便民网点和出行类设施以适配型为主。食与行 是居民最基本的需求, 大部分区域得到了充分保 障,但城市边缘区仍是漏配主发区。通讯和银行等 便民网点虽然逐渐被线上服务所代替,但在传统配 置原则和规划理念的作用下, 覆盖范围依然很 广泛。

(2) 中等覆盖型 : 这一类型有食材类和教育类 设施。其中, 食材类设施作为居民日常生活刚性需 求设施, 与 $5 \mathrm{~min}$ 生活圈中的医疗设施和出行类设 施相似, 在空间形成 5 个组团, 组团中心其配置水平 相对较高, 而组团之间形成了大面积漏配区; $10 \mathrm{~min}$ 生活圈的教育类设施为小学, 小学教育虽然是由政 府主导配置, 并进行 “划片招生”, 但现实情况中, 中 心区的学校具有吸引优秀师资力量与投人资金的 优势。因此, 教育设施的两极分化现象也比较严 重, 优质的教育资源倾向于集中分布于区级中心，
围区域需要通过 “走学”的方式来获取优质教育 服务。

(3) 低覆盖型: 此类型有医疗类设施和养老类 设施, 这 2 类设施的高配与适配型生活圈占比很低, 覆盖范围小, 漏配型生活圈占绝对优势。其中, 医 疗设施也表现出较强的两极分化现象, $10 \mathrm{~min}$ 生活 圈的医疗设施是指社区卫生服务中心, 它是以社区 为单元进行建设与管理, 发展较好的社区有能力引 导市场建立, 发展落后的社区则比较被动。七里河 区的此类医疗设施最为溃乏, 作为补充, 七里河区 $5 \mathrm{~min}$ 生活圈所对应的诊所、药店的适配与高配生 活圈的覆盖范围较广, 这反映了高级生活圈与低级 生活圈之间具有灵活的相互补充关系。而养老设 施在本级生活圈中仍然没有得到改善。

\section{$3.315 \mathrm{~min}$ 生活圈适配性}

$15 \mathrm{~min}$ 生活圈中的各类设施配置情况与 10 $\min$ 和 $5 \mathrm{~min}$ 生活圈同类设施相比, 变化有限(图 7)。消费类和教育类设施的覆盖范围与 $5 \mathrm{~min}$ 生活 
(a) 出行类设施

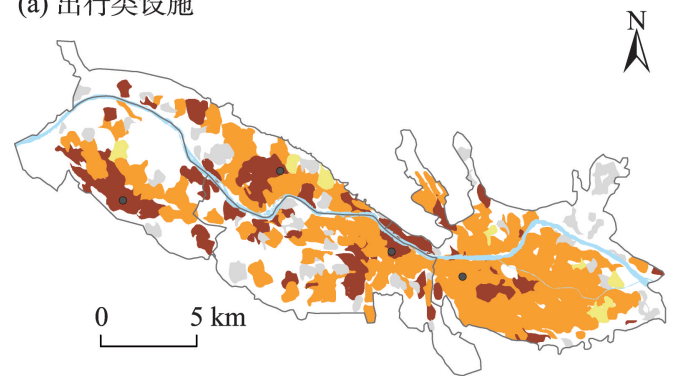

(c) 食材类设施

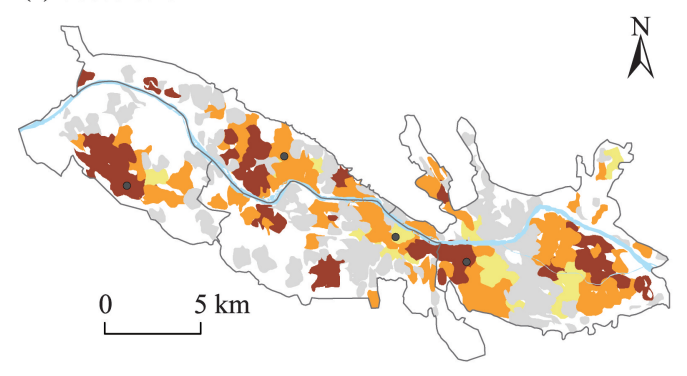

(e) 医疗类设施

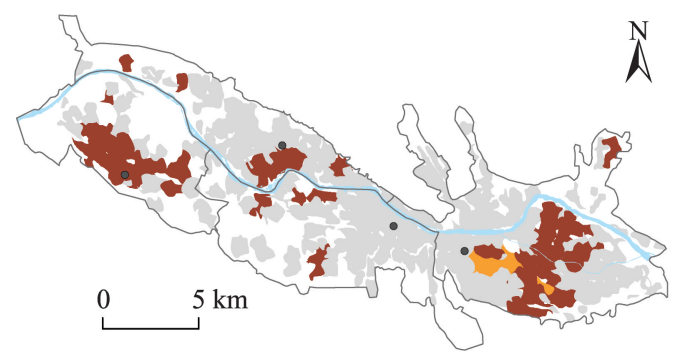

(g) 养老类设施

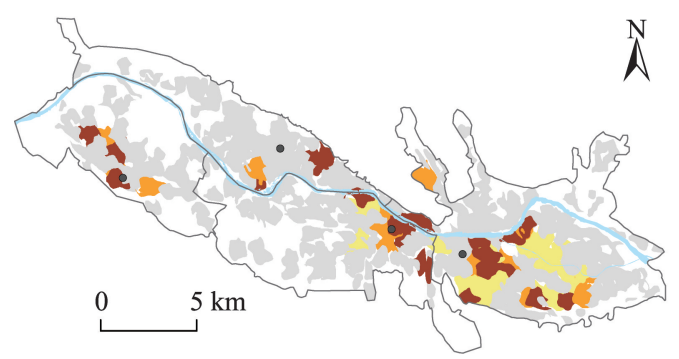

(b) 就餐类设施

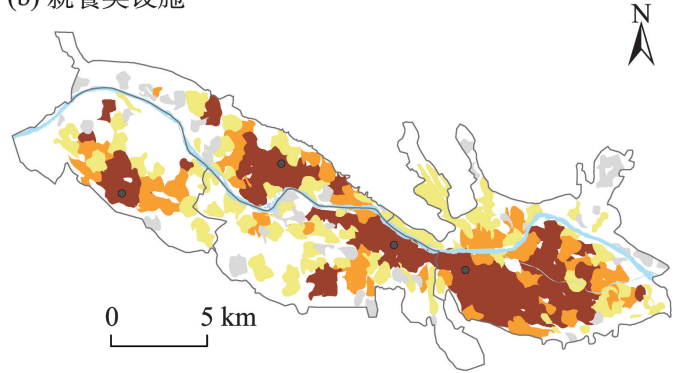

(d) 便民网点类设施

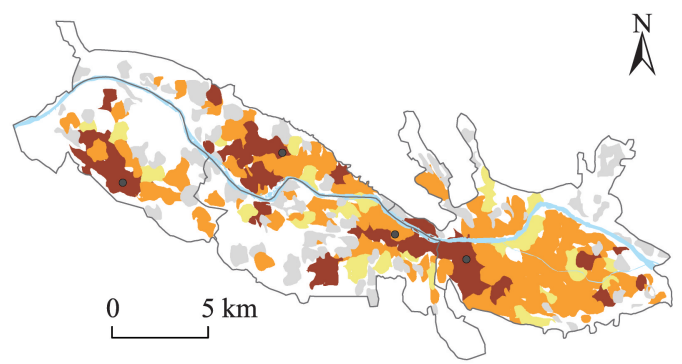

(f) 教育类设施

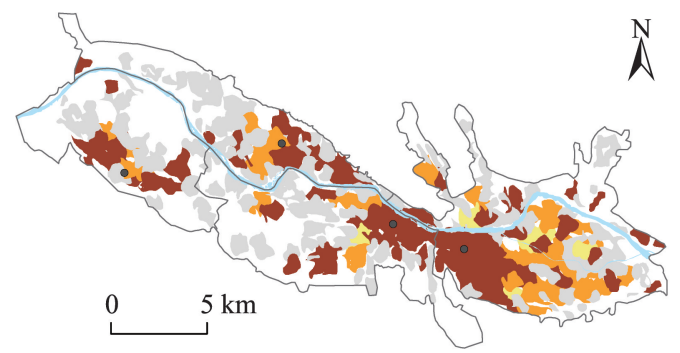

图 6 兰州市 $10 \mathrm{~min}$ 生活圈设施适配性

Fig.6 Matching relationships of public service facilities in 10-minute life circle of Lanzhou City

圈相同,也处于中等水平。养老类设施与 $5 \mathrm{~min}$ 、 $10 \min$ 生活圈相比, 只发生了位置变化, 比例依然 很低。

(1) 广泛覆盖型 : 包括娱乐类和便民网点类设 施。这 2 类设施的高配与适配型生活圈分布范围均 相对广泛,但两者又有不同,娱乐类设施的高配与 适配型生活圈分布相对分散, 在区级中心和城市边 缘均存在, 但中心的配置量稍多, 表明由市场主导 的配给娱乐设施较为充分; 便民网点类设施(物流 配送点与邮政点)的高配与适配型生活圈则主要集
中在城关区, 表现了物流业与经济、人口之间的高 相关性。

(2) 中等覆盖型 : 包括消费类、养生类和教育类 设施。这两类设施局部区域有漏配型生活圈侵人 适配与低配型生活圈的现象。其中,消费类设施的 高配与适配型生活圈和高密度居住区分布更为相 近, 这与居民的潜在需求量相契合, 也体现出了消 费类设施对城市中心的强化与塑造作用。对于由 市场主导供给的养生类设施而言, 高配与适配型生 活圈分布面积更大、覆盖范围更广。同时, 相较于 
(a) 便民网点类设施

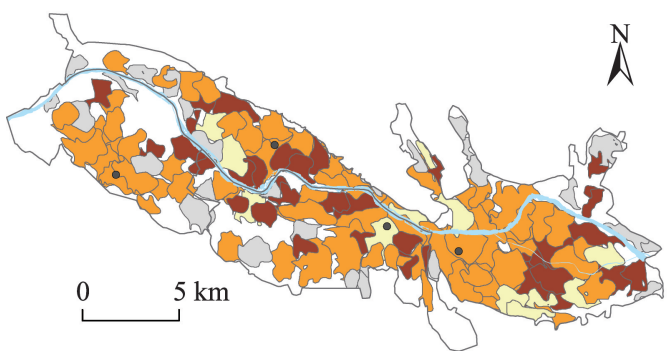

(c) 消费类设施

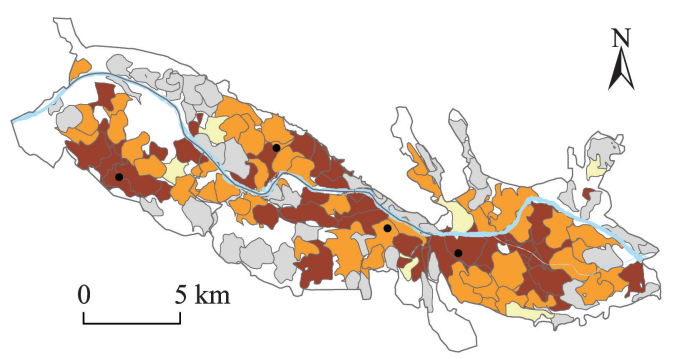

(e) 文化类设施

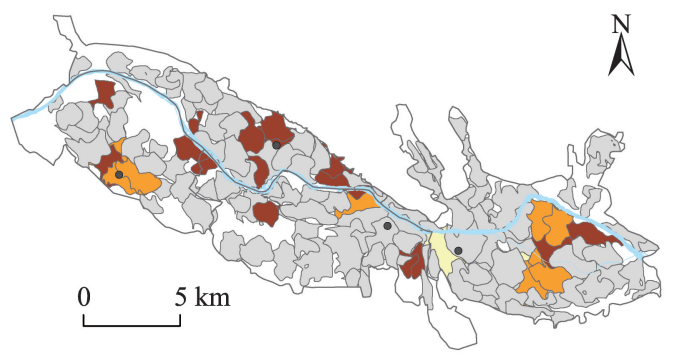

(g) 养老类设施

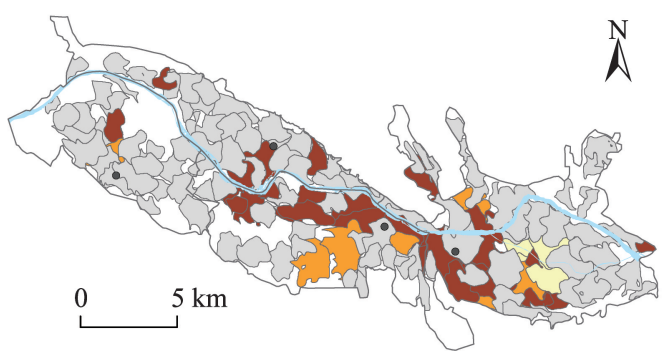

(b) 娱乐类设施

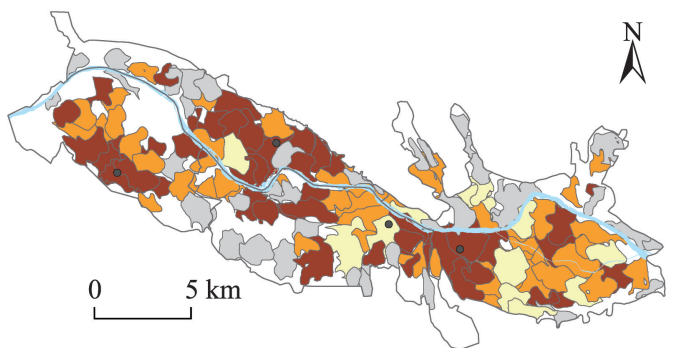

(d) 养生类设施

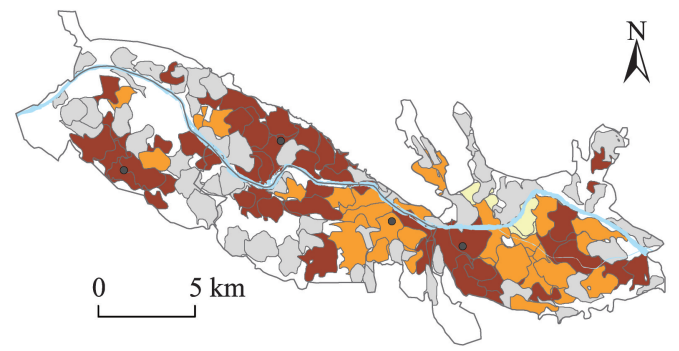

(f) 教育类设施

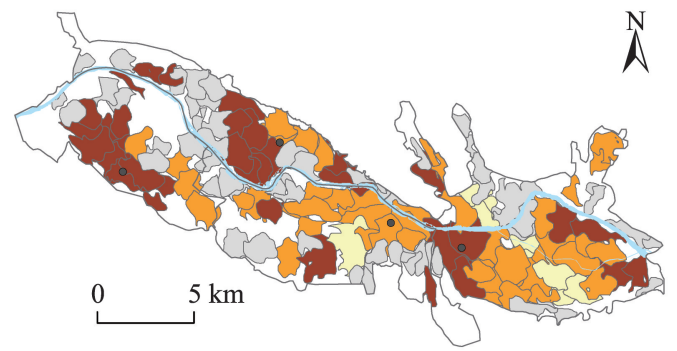

图 7 兰州市 $15 \mathrm{~min}$ 生活圈设施适配性

Fig.7 Matching relationships of public service facilities in 15-minute life circle of Lanzhou City

$5 \mathrm{~min}$ 和 $10 \mathrm{~min}$ 生活圈, 以中学为主的教育类设施 的配置水平、整体覆盖水平得到了强化提升。

(3) 低覆盖型 : 包括文化类、养老类设施。在 15 $\min$ 生活圈中这 2 类设施均以社区和街道办为依 托,由政府主导供给,漏配型生活圈成为主流存在 形式, 高配型生活圈分布较为分散。文化类设施的 高配与适配型生活圈在城关区和七里河区倾向于 边缘分布,在安宁区和西固区倾向于中心分布; 而 养老类设施主要分布在七里河与城关区 2 个区级中 心之间。

\section{4 结论}

随着人本主义思潮的发展, 中国城市规划更加 关注人的感受和情感体验,城市日常生活圈是从居 民视角出发重新考量城市规划和公共服务设施配 置, 是传统城市规划人本化、生活化的良好途径。 城市日常生活圈对于解决公共服务设施公平配置, 缩减城乡差距、区域差距, 提高居民生活便利性、促 进居民生活质量和优化基层治理有着重要意义。 本文从生活圈视角出发, 对公共服务设施与人口的 
匹配关系进行了详细评估, 研究结果表明:

(1) 从设施一人口匹配关系的空间分布来看, 匹配度的空间分异十分显著, 配置量较高的生活圈 集中分布在各行政区中心区域,而城市边缘区是漏 配型生活圈主要出现地, 成为无设施覆盖的 “死 角”; 适配型和低配型生活圈的数量不多, 分散在城 市(区)中心至边缘的中间地带。

(2) 从各类设施的高配与适配型生活圈的覆盖 范围来看, 大部分区域各等级养老类设施和基础文 化设施明显配置不足, 甚至严重短缺; 还有一些设 施高配与适配型生活圈比例最高, 覆盖范围广, 适 配关系较好, 这类设施有: 医疗类(但 $10 \mathrm{~min}$ 生活圈 的医疗设施较为缺乏)、出行类、就餐类、娱乐类和 便民网点类(物流、通讯、银行营业点); 另一些诸如 教育、食材、养生和基础消费类设施的高配与适配 型生活圈比例相对较小, 分布范围也不大。

(3) 兰州市现有生活圈的划定依然没有脱离规 划地块、街区和社区的“巢臼”, 这种以街区为划定 依据的生活圈没有将需求主体的空间分布特征、空 间活动特征等纳人考量, 并非真正意义上的生活 圈, 一定程度上会造成设施配置的偏差。

研究认为, 城市规划应充分考虑居住地对居民 的凝结作用, 将其按一定规则整合后, 以此为中心 构建城市生活圈。通过社区生活圈来提高公共服 务设施的配置效率和保障设施分配的公平性。对 于暴露的问题需要查漏补缺, 重点关注城市边缘区 各类公共服务设施的配置, 合理引导核心区的设施 向外扩散; 强化各级养老设施、基层医疗设施和基 层文化设施的覆盖水平; 创新养老设施供给制度和 供给模式,引人非市场力量或以公私合作的方式提 高传统养老设施的供给量, 推进居家养老和日间照 料等符合中国国情的养老方式的规范与普及; 对于 基层医疗设施和文化设施, 需要打造以居民需求为 导向的灵活配置方案。

\section{参考文献(References)}

[1] Yin C H, He Q S, Liu Y F, et al. Inequality of public health and its role in spatial accessibility to medical facilities in China [J]. Applied Geography, 2018, 92: 50-62.

[2] You H Y. Characterizing the inequalities in urban public green space provision in Shenzhen, China [J]. Habitat International, 2016, 56: 176-180.

[3] Taleai M, Sliuzas R, Flacke J. An integrated framework to evaluate the equity of urban public facilities using spatial multi-criteria analysis [J]. Cities, 2014, 40: 56-69.

[4] Zhang X, Wang J, Kwan M P, et al. Reside nearby, behave apart? Activity-space-based segregation among residents of various types of housing in Beijing, China [J]. Cities, 2019, 88: 166-180.

[5] Bjorklund E M. The Danwei: Socio-spatial characteristics of work units in China's urban society [J]. Economic Geography, 1986, 62(1): 19-29.

[6] Chai Y W. From socialist danwei to new danwei: A dailylife-based framework for sustainable development in urban China [J]. Asian Geographer, 2014, 31(2): 183-190.

[7] Zhou J P, Zhang C, Chen X J, et al. Has the legacy of Danwei persisted in transformations? The jobs-housing balance and commuting efficiency in Xi'an [J]. Journal of Transport Geography, 2014, 40: 64-76.

[8] Liu T B, Chai Y W. Daily life circle reconstruction: A scheme for sustainable development in urban China [J]. Habitat International, 2015, 50: 250-260.

[9] Bray D. Building 'community': New strategies of governance in urban China [J]. Economy and Society, 2006, 35 (4): 530-549.

[10] Chen J H, Guo F, Wu Y. One decade of urban housing reform in China: Urban housing price dynamics and the role of migration and urbanization, 1995-2005 [J]. Habitat International, 2011, 35(1): 1-8.

[11] Ma L J C. Economic reforms, urban spatial restructuring, and planning in China [J]. Progress in Planning, 2004, 61 (3): 237-260.

[12] 上海市规划和国土资源管理局, 上海市规划编审中心. 上海 15 分钟社区生活圈规划研究与实践 [M]. 上海: 上 海人民出版社, 2017: 147. [Shanghai Municipal Planning and Natural Resources Bureau, Shanghai Planning Editorial and Audit Center. Research and practice of 15minute community life circle planning in Shanghai. Shanghai, China: Shanghai People's Publishing House, 2017: 147. ]

[13] 袁家冬, 孙振杰. 关于我国城市统计区重建的地理学 研究 [J]. 地理科学进展, 2005, 24(4): 11-18. [Yuan Jiadong, Sun Zhenjie. A geography study on reconstruction of urban statistical area in China. Progress in Geography, 2005, 24(4): 11-18. ]

[14] 柴彦威. 以单位为基础的中国城市内部生活空间结构: 兰州市的实证研究 [J]. 地理研究, 1996, 15(1): 30-38. [Chai Yanwei. Danwei-based Chinese cities' internal lifespace structure: A case study of Lanzhou city. Geographi- 
cal Research, 1996, 15(1): 30-38. ]

[15] 陈青慧, 徐培玮. 城市生活居住环境质量评价方法初探 [J]. 城市规划, 1987, 11(5): 52-58, 29. [Chen Qinghui, $\mathrm{Xu}$ Peiwei. Preliminary study on the evaluation method of urban living environment quality. City Planning Review, 1987, 11(5): 52-58, 29. ]

[16] Tian Y S, Kong X S, Liu Y L. Combining weighted daily life circles and land suitability for rural settlement reconstruction [J]. Habitat International, 2018, 76: 1-9.

[17] 韩增林, 李源, 刘天宝, 等. 社区生活圈公共服务设施配 置的空间分异分析: 以大连市沙河口区为例 [J]. 地理 科学进展, 2019, 38(11): 1701-1711. [Han Zenglin, Li Yuan, Liu Tianbao, et al. Spatial differentiation of public service facilities' configuration in community life circle: A case study of Shahekou District in Dalian City. Progress in Geography, 2019, 38(11): 1701-1711. ]

[18] 刘嫱. 基于手机数据的居民生活圈识别及与建成环境 关系研究 [D]. 哈尔滨: 哈尔滨工业大学, 2018. [Liu Qiang. Mobile phone data identification of residents' life circle and its condition with the built environment. Harbin, China: Harbin Institute of Technology, 2018. ]

[19] 余思奇, 朱喜钢, 刘风豹, 等. 社会公平视角下城市公园 绿地的可达性研究: 以南京中心城区为例 [J]. 现代城 市研究, 2020, 35(8): 18-25. [Yu Siqi, Zhu Xigang, Liu Fengbao, et al. The evaluation of accessibilities to urban Parks from the perspective of social justice: A case study of Nanjing. Modern Urban Research, 2020, 35(8): 18-25. ] [20] 周弦. 15 分钟社区生活圈视角的单元规划公共服务设
施布局评估: 以上海市黄浦区为例 [J]. 城市规划学刊, 2020(1): 57-64. [Zhou Xian. Assessing the distribution of public service facilities in unit planning based on the perspective of the 15-minute community-life circle: Evidence from Huangpu district of Shanghai. Urban Planning Forum, 2020(1): 57-64. ]

[21] 王圭. 基于生活圈的首都功能核心区居住公共服务设 施配置指标优化研究 [D]. 北京: 北京建筑大学, 2020 . [Wang Yao. Research on the optimization of the allocation index of the residential public service facilities in the core area of the capital function based on the life circle. Beijing, China: Beijing University of Civil Engineering and Architecture, 2020. ]

[22] 柴彦威, 李春江. 城市生活圈规划: 从研究到实践 [J]. 城市规划, 2019, 43(5): 9-16, 60. [Chai Yanwei, Li Chunjiang. Urban life cycle planning: From research to practice. City Planning Review, 2019, 43(5): 9-16, 60. ]

[23] 王录仓, 常飞. 基于百度热力图的银川市中心城区职住 关系研究 [J]. 干旱区地理, 2019, 42(4): 923-932. [Wang Lucang, Chang Fei. Jobbing-housing relationship in central urban area of Yinchuan City based on Baidu heat map. Arid Land Geography, 2019, 42(4): 923-932. ]

[24] 孙道胜, 柴彦威, 张艳. 社区生活圈的界定与测度: 以北 京清河地区为例 [J]. 城市发展研究, 2016, 23(9): 1-9. [Sun Daosheng, Chai Yanwei, Zhang Yan. The definition and measurement of community life circle: A case study of Qinghe area in Beijing. Urban Development Studies, 2016, 23(9): 1-9. ] 


\title{
Do urban public service facilities match population demand? Assessment based on community life circle
}

\author{
CHANG Fei ${ }^{1,2}$, WANG Lucang ${ }^{3 *}$, MA Yue ${ }^{3}$, YAN Cuixia ${ }^{3}$, LIU Haiyang ${ }^{3}$ \\ (1. School of Architecture and Urban Planning, Shenzhen University, Shenzhen 518000, Guangdong, China; \\ 2. Research Institute for Smart Cities, Shenzhen University, Shenzhen 518000, Guangdong, China; \\ 3. College of Geography and Environmental Science, Northwest Normal University, Lanzhou 730000, China)
}

\begin{abstract}
Public service facilities (PSF) are the basic guarantee for urban production and living. Whether the distribution of public service facilities is equitable is related to the healthy development of cities and the society. At present, due to the lack of urban micro-scale population distribution data, there are few studies that consider both the supply side (PSF) and the demand side (population). In view of this, using the Internet maps application programming interface (API), this study established the 5-minute, 10-minute, and 15-minute community life circle of Lanzhou City, and then used Worldpop grid data, population census data, and Baidu heat map data to simulate the population distribution at high spatial resolution and with high accuracy. We evaluated the matching relationships between population and public service facilities in Lanzhou City. The study found that: 1) The matching relationships between different types of PSF and population are very different. However, they show a common phenomenon that the matching degree close to district administrative centers is often better than that of urban fringe. 2) In Lanzhou City, the matching relationships between PSFs and population are highly polarized, that is, there are more highly matched and mismatched life circles, and the number of moderately matched and relatively poorly matched life circles is fewer. 3) Based on the coverage of moderately and highly matched life circles, the coverage of all levels of travel, medical (except community health service centers corresponding to 10-minute life circle), dining, and entertainment facilities is the widest. The allocation of elderly care facilities at all levels and grass-roots cultural facilities is seriously inadequate, and other facilities are between the two types. The study concludes that the problems that have been identified need to be addressed. It suggests that urban planning should focus on the allocation of various PSF in the urban fringe, and improve the coverage of all levels of elderly care facilities.
\end{abstract}

Keywords: public service facilities; community life circle; matching relationship; adaptability; population; Lanzhou City 